\title{
Role Ambiguity, Goal Orientation and Turnover Intention among Faculty Members of Private Sector Universities
}

\author{
Samreen Gilani \\ Riphah Institute of Clinical and Professional Psychology \\ samreensyed92@gmail.com
}

\author{
Anum Rabbani \\ Riphah International University Lahore, Pakistan
}

\begin{abstract}
The research was conducted to examine the relationship between, role ambiguity, goal orientation and turnover intention among faculty members of private sector universities and also to find out the moderating role of goal orientation in the relationship between role ambiguity and turnover intention. It was hypothesized that there would be a significant relationship among role ambiguity, goal orientation and turnover intention. It was also hypothesized that role ambiguity would predict turnover intention among teachers of private sector universities. Another hypothesis was that goal orientation would moderate the relationship between role ambiguity and turnover intention. And last hypothesis was that there would be significant relationship among demographic variables, role ambiguity, goal orientation and turnover intention. A sample of 250 faculty members $(\mathrm{N}=250)$ age 30-45 (125 Male; 50\%, 125 Females; 50\%) of different private sector universities of Lahore was taken. The Role Ambiguity Scale (Rizzo et al., 1970), Goal Orientation Scale (Button, Mathieu \& Zajac, 1996) and the Turnover Intention Scale (Roodt, 2004) were used to measure the study variables. Correlation analysis showed that there is positive relationship between role ambiguity and goal orientation. Role ambiguity and turnover intention have negative correlation. The results also showed that there is negative relationship between goal orientation and turnover intention. Findings also revealed role ambiguity to be the most significant predictor of turnover intention. Results also reported that there were nonsignificant gender difference in role ambiguity, goal orientation and turnover intention. The study can be implicated for many people including psychologists, teachers, researchers, business administrators, industrial workers and employees also helpful for them as well as their family.
\end{abstract}

Keywords. Goal orientation, Role Ambiguity, Turnover Intention, Employees, Universities

\section{Introduction}

Firms increasingly understood that workers were the way to their prosperity and view manager Workers relationship as a commonly helpful procedure. Hierarchical publication characterized how a firm tended to the benefits of its workers and in what way that was imitated to its greatest advantage. Authoritative assimilation assisted both the firm and his Workers to address their issues (Chow, 2006). The main time frame now linking a firm is basic for innovative Workers. An essential reason of authoritative publication rehearses is that the 
idea of another Workers underlying encounters is basic to his acclimation to the new condition (Fogarty, 1992; Saks \& Ashforth, 2008).

Because of the way that another worker may confront a situation once they link the firm, the firm would focus upon the most capable method to lessen his/her exposure and fear. Effective authoritative publication increments enthusiastic connections toward the firm. Further, public firms with different workers are essential during the time spent authoritative publication (Kato, 2010).

The connection between a firm and its Workers is both basic and delicate. From various perspectives, it is a trade relationship in which the two parties convey to the table something different needs or needs. Be that as it may, long haul firm workers connections are regularly influenced by numerous variables, for example, authoritative culture and public fulfilment, which would thusly influence whether a Worker means to remain with or leave the firm. As high-playing out workers' intentional turnover is particularly negative to authoritative performance (Kwon \& Rupp, 2013).

The consistent communication between an individual and other individuals is known as the publication procedure. It is in this procedure that an individual accept a job, position, status, or obligation that is required or requested for a specific setting. In the hierarchical setting, for instance, an individual can expect a job that requires him/her to go about as manager, and simultaneously, he/she can go about as subordinate to another region, thus his/her duties will be diverse for every last one of the positions (Monnot, 2008).

Public brain science writing makes reference to that the investigation of job hypothesis goes back to the 1930s. In the authoritative setting, the investigation of this hypothesis goes back to the period somewhere in the range of 1950 and 1960, in which the principal specialists were Kahn, Wolfe and Quinn, which at the time previously began to point on the presence of hierarchical strains in laborers while they played out their errands.

As per Katz and Kahn (1970), Fisher (2001), and Fichter (2011), the two kinds of authoritative strains most featured in the writing are job conflict and role ambiguity, which can begin from the nearness of hierarchical, individual and relational elements, which influence the view of administrators while satisfying their duties.

As indicated by Ruler and Lord (2007), the sending of the prerequisites of the job designators (prompt bosses) to the individual in charge of a position happens by means of immediate and aberrant correspondence between them. In this situation, it is critical to realize what are the occupant elements of every last one of the designators, also, as taking consideration with the clarity of the required.

\section{Role Ambiguity}

Role ambiguity, the most vigorously looked into job recognition, is described as a person's absence of clarity or understanding of his or her job (Kahn et al., 2009). For instance, a person who is getting misty data or data from numerous sources may encounter Role ambiguity and along these lines not completely comprehend what his or her obligations are inside the gathering.There are four general angles to a person's job that he/she should follow: (a) the extent of his/her job duties (i.e., the extent of obligations that the job involves), (b) the practices important to satisfy his/her job (i.e., what activities are required to attractively finish his/her job duties), (c) how his/her job performance will be assessed (i.e., what criteria his/her performance will be made a decision by), and (d) the results of neglecting to satisfy the job obligations (i.e., the incompatible results that will result from not finishing his/her job (Eys \& Carron, 2009). 
Role ambiguity states to the impression of uncertain or unsure job desires. The failure to see an unmistakable conduct desire decreases the chance of a desire will be followed up on, improving the possibility of relational clash and apparent absence of adequacy inside the authoritative job. Job conduct desires should originate from a reasonable and bound together source (Abrahamson, 2008).

Fisher (2001) says that ambiguity in role is brought to the world when an authority has no significant information that gives it the power to fulfil its commitments effectively. This information should give confirmation of appropriate uncertainties about the performance of a vocation, likewise as its augmentation in term of rights commitments and obligations; (i)Specific action, in the same way as methods or best way to achieve this, which effectively fulfills a position commitments; (ii) results and non-compliance; (iii) compliance which is balanced or penalized, nature of reward and penalties, conduct acceptable or unacceptable in the performance of the person; (iv) open access to growth.

In order to carry out this research, Role ambiguity is agreed by the disputes by the makers Singh and Rhoads (1991, as referred to in Lee, 2010) \& Fisher (2001). Role ambiguity has been characterized as lack of project consistency and objectives, liability over the specialist or learning on the most capable method to perform doled out occupations (jobs) (Rizzo et al., 1970). Sinha \& Subramanian (2012 referred to role-ambiguity like the stage of insecurity that people perceive in fulfilling their roles and lacking the expectations of role-based action performance. Onyemah (2008) has described role-ambiguity as a lack of confidence in workers, while Shoemaker (2006) considers role-ambiguity to represent a change in workers ' employment.

As per Hartenian et al. (2011), role ambiguity is the contrast among estimated and supposed persons or the lack of job clearness. Job clearness is characterized as the degree to which workers jobs are unmistakably conveyed and comprehended by them. In an investigation of interconnections of job struggle, role ambiguity, and community-job strife with various aspects of employment fulfillment, Boles et al. (2013) called attention to that apparent absence of clarity goes before role ambiguity. Job clearness has been reasonably characterized by Rizzo et al. (1970) as the degree to which a worker understands whatever is estimated from that person for suitable performance of his undertakings and occupation obligations.

Ambiguity of roles results when an individual gets indistinct guidelines regarding his obligations and activities, prompting work pressure. It is said to exist when a Worker gets ambiguous and indistinct desires prompting insecurity of what is anticipated from him. Workers asked to encounter role uncertainty if they're having synchronous then opposing desires of their own work partners to do so troublesome To finish the assignments (Katz \& Kahn, 2005).

Ambiguity of role relates to the unclearness about the desires and solutions for a particular task (Rahim, 2011).As indicated by Olaleye and Arogundade (2013), it is a circumstance how personal need clearness of what they think of each other, not well characterized jobs, and that it drives job conflict.As indicated by Kahn, et al. (2007), role ambiguity is a mode of insufficient Roles that send "a direct function of the discrepancy between the information available to the person and that which is required for adequate performance of his [or her] role." They have moved on express whether a person wants encounter pressure, fewer fulfillments and work less successfully once the planned activities with them are conflicting, confounding or even clashing instead desires forced upon them are to some degree strong and predictable. It is likely that there is a weight in the form of job 
dispute and the position of the scholastics and managers when they are struggling to reach agreement in formal management when they approach groups within and out of the firm.

The degree of ambiguity for absence in fair data connected with a job plus insecurity for the aftereffect for a person's job exhibition (Beena, 2009). Hsieh and Hsieh (2013) believe that role ambiguity could be because of deficient data with respect to a worker job or absence of comprehension of what is anticipated from him. This definition is in concurrence with Idris (2011) see who characterizes role ambiguity as if a single person needs fair expert or information on the most capable method to play out his relegated jobs.

Schulz and Auld (2006) suggest that role ambiguity is because of misty appropriation of intensity, progressive system, obligations or person's exercises. Yongkang et al., (2014) characterized role ambiguity as level of job desires, methods for satisfying the job desires and the punishment of job performance. The interpretation of this research is used Idris (2011).

Role ambiguity is the decision that anyone needs details critical for playing out a livelihood or job, driving the interpreter to sense unprotected. It's a worker's weakness regarding different members ' expectations in their position (Onyemah, 2008). Every official position should be clear in a framework effort required to avoid misperception and raise efficiency; anyway in specific assemblies job necessities are unsure (Hamilton, 2012).

Role ambiguity outcomes from lacking details or awareness to complete an obligation. This uncertainty can be a result of preparation, reduced communication, or the thoughtful maintenance or twisting of details by a teammate or director (Luthans, 2006). To whole things up, we can say that sensible arrangements of desires and apparent master Firms can add to handling vague issues. Right if people know everything, nuances From theirs circumstance in the affiliation, they imagine that it's pleasant to accept obligation for their exercises and to interface with others.

Role ambiguity, or the degree to which one's work duties and level of power are unclear, is a standout amongst the most broadly planned factors in the field of word related pressure. Since it speaks to an emotional judgment of one's work circumstance, Role ambiguity is generally assessed using self-reports from workers. Some researchers consider confusion because of its polar opposite, clarification of positions.

Workers with role ambiguity in positions feel uncertain about what behaviors are and are not acceptable. They may consider, for instance, regardless of whether they are taking part in unseemly work practices. Then again, they may consider whether they are ignoring to contribute in suitable effort practices. Both these conditions are upsetting for most staff. (Beehr, Walsh, \& Taber, 2010).

A significant part of the examination on word related pressure has concentrated on recognizing job pressure; role ambiguity and a related variable, called job dispute (i.e. To what degree an worker is faced with inconsistent work requirements), are the most regularly considered stressors. A stressor is any part of the workplace that requires a Worker to adjust and can possibly cause weakness. The negative wellbeing results delivered by a stressor, for example, depression, anxiety, or physical symptoms, are called strains (Beehr, Walsh, \& Taber, 2010).

The theory of roles provides the theoretical framework for the role ambiguity analysis. According to role theory, every worker has a special arrangement of rights and duties inside the firm. Formal jobs are the arrangement of authority practices that workers execute as an aspect of their responsibilities portrayal and are kept up by hierarchical strategies (Fisher \& Gitelson, 2013).

The formal role of a teacher involves testing and homework assignment. Therefore, informal responsibilities evolve as part of the firm's daily public dynamic. For educators, for 
instance, casual jobs may incorporate arranging and sorting out staff parties. Role ambiguity is for the most part operationalized as uncertainty concerning formal jobs (Fisher \& Gitelson, 2013).

As indicated by leadership theories, great leader's help workers clear up their obligations and afterward make circumstances in which those duties can be successfully executed. By this standard, compelling pioneers make work circumstances for their subordinates that are free of role ambiguity. At the point when role ambiguity arises, powerful pioneers work to limit it. Initiative hypotheses additionally propose that viable pioneers show worry for the individual welfare of their subordinates. To the degree that supervisors care about worker prosperity, they are probably going to move in the direction of decreasing role ambiguity and different stressors (Jackson \& Schuler, 1985).

The theory that active leading behavior is associated with low rates of position uncertainty backed by empiric proof. For example, two competencies related to the low position uncertainty are leading the induction framework (i.e. the level of involvement of officials on compatibility to explain their worker responsibilities) and leading concern (i.e., the level to which officials care for their workers). (Jackson \& Schuler 1985)

Moreover, workers are probably going to encounter little role ambiguity when their leaders give chances to Workers cooperation and make a formalized workplace. To put it plainly, role ambiguity is characteristic of poor administration rehearses. Without a doubt, many overview things estimating role ambiguity make explicit reference to one's supervisor (Kahn \& Byosiere, 2005).

Anyhow the negative practices of Supervisors, workers who report elevated amounts of role ambiguity by and large report having troublesome workplaces. A portion of the natural components related with role ambiguity are absence of self-governance, input, and job personality. At the end of the day, role ambiguity is well on the way to happen in basic, enriched employments. Moreover, workers who report higher amounts of role ambiguity additionally by and large report abnormal amounts of job struggle (Kahn \& Byosiere, 2005).

Singular contrasts may incline people to encounter role ambiguity. Individuals with an internal power vector (i.e., the individuals those trust they have little power over their lives), who are high in neuroticism, who are high in requirement for clarity, or who have low confidence, for instance, are particularly responsible to report abnormal amounts of role ambiguity (Kahn \& Byosiere, 2005).

Impressions of uncertainty are at the center of numerous work environment stressors, and role ambiguity is no special case. Uncertainty can result in many negative outcomes. Surely, a few examinations have demonstrated that role ambiguity is identified with appearances of poor mental and physical wellbeing. For instance, role ambiguity is related with tension, burnout, gloom, and physical ailment.

Anyhow this negative wellbeing outcome, role ambiguity is related with both negative worker's frames of mind and ineffectual occupation practices. Meta-examinations, for instance, have discovered that role ambiguity is related with the accompanying frames of mind:

Overall work disappointment

Dissatisfaction with work undertakings

Dissatisfaction with supervision

Dissatisfaction with colleagues

Low hierarchical responsibility

Low work contribution

High turnover expectation 


\section{Absenteeism}

The connection between role ambiguity and disappointment with supervision is particularly solid, recommending that Workers see the board as the wellspring of role ambiguity. Significant methodological issues include the investigation of role ambiguity. The vast majority of the exploration analyzing the causes and results of role ambiguity has utilized cross-sectional plans (Katz \& Kahn, 2008).

Firms have a few alternatives obtainable to them for treating role ambiguity. Meanwhile ineffectual authority is a root cause of role ambiguity; the most inspiring medicines are likely to have pioneers. Those treatments might include the following actions:

- Preparing administrators to recognize if their practices may prompt job Uncertainty and urging them to alter these practices.

- Consider managers likely to participate in strong initiating systems and considerations

- Reforming employments to be progressively unpredictable.

- Presenting endeavors went for diminishing job struggle.

Given the negative results related with role ambiguity, one may expect that firms would be extremely energetic to limit the dimensions of role ambiguity and their workers ' expertise. Be that as it may, as firms center more on the main concern, threatening working environments and their bad impacts on workers are frequently disregarded. (Katz \& Kahn, 2008).

\section{Goal Orientation}

The idea of goal orientation developed during the (1980s) from an investigation directed with grade level understudies by Dweck and her partners. It looks at people's way to deal with, commitment in, and reactions to their scholastic work. In the blink of an eye, why and how they attempt to achieve diverse goals. The reasons can shift among people, for example, being keen on learning or showing improvement over others.

Dweck (1985) purposed two classes of objectives that people convey in accomplishment circumstances. Research has demonstrated that these objectives uncover suggestions for the assignments understudies pick, how they approach these undertakings, how they respond to the results, and at last, what they learn (Elliot and Dweck,2010). Goal orientation is a significant dispositional trademark identifying with workers performance in Firms (e.g., Basement et al., 2011; Payne et al.2007). Goal orientation portrays the disposition of a person toward creating or showing capacity in accomplishment circumstances or individual contrasts in inspiration to create or exhibit skill (Payne et al., 2007; VandeWalle, 2005).

There are three elements of goal orientation generally talked about in the writing. These three measurements are learning, performance approach, and performance avoid from goal orientation. Learning goal orientation is the measurement concerning to what grade a person tries to create and obtain new abilities (VandeWalle, 2005; VandeWalle et al., 2007; VandeWalle et al., 2006). Performance introduction is the degree to which an individual is persuaded to demonstrate skill by increasing positive decisions and keeping away from horrible decisions (VandeWalle, 2005; VandeWalle et al., 2006; VandeWalle et al., 2007).

The performance approach measurement is the degree to which an individual is looking for positive decisions and the performance keep away from measurement is the degree to which an individual is trying to evade horrible decisions. Fluctuating dimensions of each measurement decide the manner in which an individual characterizes achievement, capacity, and objectives (Payne et al., 2007).

These unique elements of goal orientation similarly influence the significance an individual joins to hard work and his or her desire for criticism. Each of the three dimensions 
has been observed to be essential to the representation of manners towards creating and showing capacity (Payne et al., 2007).

People who are high or low on these measurements have been appeared to react diversely in shifting circumstances. All things considered, Payne and associates (2007) have recognized that the goal orientation writing is deficient with regards to research and interpretation of results, frequencies, and responses because of the particular profile blends of goal orientation measurements.

\section{Learning (Mastery) Goals}

Learning focused students are keen on growing their skill. As Kaplan and Maehr (2007) state, it refers to "a motivation behind self-improvement and development that guides achievement related conduct and task commitment".

Learning goal orientation is the component of inspirational introduction showing the degree to which an individual tries to build up their capability by getting new abilities and acing new circumstances (VandeWalle, 2006). A person with a high learning goal orientation characterizes attainment like authority and is constantly moving in the direction of new, testing objectives. Those with a high learning goal orientation have been found to utilize a steady hypothesis of capacity (VandeWalle, 2007).

Incremental theory of capacity is utilized when an individual perspectives capacity as a changing trait that can be created through effort and experience (Elliott and Dweck, 2007; VandeWalle, 2009). This view drives those high on learning goal orientation to work to expand their capacity through training and effort. Numerous positive results have been identified with scoring high on learning goal orientation (e.g., Basement et al., 2011).

Learning goal orientation has been observed to be identified with deals performance through self-guideline strategies, for example, objective setting, effort, and arranging (VandeWalle et al., 2006). Learning goal orientation has equally been appeared to be definitely identified with client introduction of salesmen (Harris, Mowen, \& Darker, 2005). Somebody high on taking in goal orientation profits by the gradual hypothesis of capacity and spots an incentive in purposeful effort to expand performance. It has equally been discovered that learning goal orientation has a Positive firm with criticism through objective setting, effort, and self- adequacy (VandeWalle et al., 2001).

Once more, the self-guideline events lead an individual high on taking in goal orientation to profit by criticism. Different findings reveal that these people really look for more performance and personal growth criticism as opposed to self-approval input than others (Janssen \& Prins, 2007; Madzar, 2001). Research has additionally appeared high learning goal orientation is identified with positive preparing natures for men, however not for ladies (Narayan \& Johnson, 2007).

Learning goal orientation has equally been observed to be decidedly identified with preparing self-adequacy (Chiaburu \& Marinova, 2005). A meta-investigation of the goal orientation examined learning goal orientation was emphatically identified with self-viability, self- set objective dimension, learning systems, criticism chasing, reduced state nervousness, learning and scholarly performance, and undertaking and employment performance (Payne et al., 2007).

Further, this equivalent meta-investigation found that learning goal orientation expected occupation performance well beyond subjective capacity and the Huge Five identity characteristics. This gives proof that persuasive introduction gives extra description of people past fundamental identity and knowledge. 
Elliott and McGregor (2001) have proposed a fourth component of goal orientation that would isolate the learning goal orientation measurement into a learning approach and a learning neglect measurement. In spite of the fact that adding to the symmetry of (VandeWalle, 2007) three dimensional measure, there isn't clear proof that this fourth measurement contributes extra clarification Along these lines, the learning shirking measurement appears to speak to somebody who is essentially high on both learning and performance maintains a strategic distance from goal orientation. The three factor measures have been all the more convincingly approved (Elliot \& Harackiewicz, 2006; Elliot et al., 2008) and this fourth measurement is moderately more current with less help (Whingter, Cunningham, Wang, \& Burnfield, 2008). Additionally, endeavors to make a saturnover intention scalefactory proportion of the learning evasion measurement appear to be to some degree tricky (Baranik, Barron, \& Finney, 2007).

Ongoing thorough examinations of goal orientation writing have not inspected the learning stay away from measurement because of an absence of research and constrained observational information to help this refinement (e.g., Basement et al., 2011; DeShon \& Gillespie, 2005; Payne et al., 2007). Because of an absence of calculated or genuine substantiation, this element of goal orientation won't be analyzed in the present investigation.

\section{Performance Goals}

Performance arranged students are keen on exhibiting their ability. Studies show results- oriented strategies to avoid challenging tasks due to failure anxiety (Dweck \& Leggett, 2009).

Performance goal orientation is depicted like to what grade a person tries to show and approve the adequacy of their capability by looking for positive decisions and maintaining a strategic distance from negative decisions (VandeWalle, 2011).

An individual high on either performance goal orientation measurement characterizes accomplishment through results and perspectives dimension of effort as a sign of capacity. Elite goal orientation is identified with an element hypothesis of capacity (VandeWalle, 2005). An entity theory of capability is when capability is observed as a stable and constant individual property (Elliott \& Dweck, 2008 VandeWalle, 2010).

Having an entity theory of capacity drives people to fear disappointment since it is a pointer of potential performance, feel undermined by criticism, and trust that less effort shows a more noteworthy capacity.

Performance approach goal orientation identifies with the manner in which an individual looks to exhibit the ability by increasing positive decisions (VandeWalle, 2006). An individual high on this measurement puts a ton of significant worth in positive results that originate from little effort, demonstrating high normal capacity.

People high on performance approach goal orientation deliberately center on exercises and assignments that are sure to prompt achievement. Criticism has minimal positive or negative impact on these people since they are just showing capacity in accomplishment circumstances in which they are certain to succeed (VandeWalle et al., 2001).

People high on performance approach goal orientation are more averse to look for personal development criticism than others (Janssen \& Prins, 2007). This measurement represents the degree to which people pick errands that are probably going to give achievement and constructive assessments. A meta-expository audit of goal orientation found that performance approach goal orientation is decidedly identified with learning systems and abnormal amounts of state nervousness (Payne et al., 2007). 
Nevertheless that performance approach was to a great extent observed to be random to results inspected in this examination, finding of little positive Firms with both learning goal orientation and performance avoid goal orientation recommends a complex relationship among dimensions. Performance approach goal orientation may give further understanding and relationship to results in blend with different measurements.

Performance maintains a strategic distance from goal orientation is the degree that an individual looks to demonstrate skill by evading negative decisions (VandeWalle, 2006). People high on the performance stay away from dimension will in general view capacity, effort, and accomplishment similarly as those high on performance approach, but are especially motivated to avoid unsuccessful outcomes. The entity theory of ability and a high fear of failure leads these individuals to avoid negative outcomes, often through avoiding achievement situations altogether. Performance avoid goal orientation has a negative relationship with feedback (VandeWalle et al., 2005).

However, Janssen and Prins (2007) found that being high in performance maintain a strategic distance from goal orientation was emphatically identified with looking for selfapproval and personal growth input. Beforehand, it was trusted that people high on this dimension would be adversely influenced by input (VandeWalle, 2005).

Any criticism incorporates the likelihood of containing the negative decisions that they emphatically try to keep away from. In any case, late research appears to demonstrate that we don't completely comprehend this relationship. Park, Schmidt, Scheu, and DeShon (2007) found that it is both goal orientation and cost and esteem observations which influence input chasing.

Payne and partners (2007) found in their meta-examination that the performance avoidance is negatively linked to oneself-efficacy, self-setting aim, input seeking, severe depression, training, work presentation and job presentation. It is clear that high levels of performance avoid goal orientation alone do not lead to successful individual or formal outcomes.

\section{Turnover Intention}

Turnover intention is the deliberate decision of a worker to depart a firm (Yang, Tsai, \& Tsai, 2014). Worker's turnover intention is one of the issue need to focus by the HR office (Peterson, 2005). Turnover intention is worker action aimed at quitting the current place of employment. Mobley (2005), explained turnover, is the end of the involvement of people with an institution who have been used by the institution. Cost (2011), notice that Turnover expectation is the form of person removal from an entity.

Turnover intention can also be characterized as knowledge and willingness to pursue other employment opportunities (Tett \& Meyer, 2005). As indicated by Jaros (2007), there have been three sign demonstrating that the Workers turnover intention. The sign is whether workers considers stopped, looks for other business openings and structures an aim to leave. Bigliardi, Petroni and Ivo Dormio (2005), also clarify that the desire to leave is a worker who wishes they should leave or stay in the current firm of employers.

Turnover is the real act that workers had leaved the association and transfer to other association for novel work links (Cost, 2011). Then again, turnover expectation is public that workers considering exit and fire for the present business affiliation that was not genuine activity to leave the present place of employment (Cotton \& Tuttle, 2005). Ajzen and Fishbein (2006), accepted those goals are the best reasonable to clarify of genuine activity.

Zhao et al., (2007), claimed that the purpose of turnover is detrimental to real turnover, particularly once the monetary crunch cannot really occur in firms. In fact, turnover intention 
will also effect in certain benefits and downsides for the workers who have done it (Joarder et al., 2011). Mobley (1982) indicated that the turnover of workers might have negative and positive effects. This has the negative consequences of breaking the current public networks, being unable to adapt to the new environment of firm, etc. Thus career growth; higher wages, better performance prospects etc. are included in the positive consequences.

The intention of turnover is the final phase of real turnover. Arnold and Feldman (2006) expressed that the intention to overturn is the conduct which directly effects on real turnover (as referred to in Masri, 2009). Bigliardi, Petroni and Dormio (2005), equally demonstrate that turnover is influenced by disappointment of workers by the employed circumstance or distinct purpose, for example, poor presentation. Carmeli (2008), have demonstrated that turnover intention is characterized as a sign of Workers' real turnover. Mobley (2009), have remarked that turnover expectation and genuine turnover have a fundamental effect to firm.

There are numerous broadly known perspectives with respect to turnover intentions, for example this idea involves a negative meaning of the board inability to inspire and hold Workers. Worker's turnover is an exorbitant consumption, particularly in Lower paid work where the pace of Workers turnover stays to be the most astounding.

Sierra and McLeavety (2005) guaranteed that turnover intentions rise up out of the conviction that public connections form after some period into credulous, steadfast, plus shared responsibilities, among together a firm and his workers. The Exchange Theory sets that public connections are portrayed through particular enthusiastic impacts of various trade configurations, in this the venture of cash and phase in humanoid investment really make inspirational mentalities and an air of respect towards the firm.

As such, a sound domain in a firm is returned decidedly in the sentiments and feelings of the staff all in all, and, thus, their aim to quit ought to be at last diminished. Its training can include offering compliments to colleagues, indicating backing to associates, keeping up a decent progression of records inside the firm, having global marketing, and cultivating connections among Firms and their clients. As a result, this particular hypothesis is effectively connected in an administrative setting.

Thirdly, Search Theory, in an authoritative setting, suggests that an extraordinary alarm should be payable towards the perfect methodology of a worker after a person picks a business proposal through a gathering of different openings for work.

The lack of understanding of a person with respect to the workers marketplace, the use of anything is related to be like "reservation price", support in finding different career options outside the present company. By and large, the least compensation or turnover plan pay was characterized as the cost of a booking, at which step an individual contemplates the acknowledgment of a work opportunity that might be characterized experimental, which might be used by people to consider whether to acknowledge or dismiss the extend of an employment opportunity in light of negligible extra data that curtails from the work turnover intention scale (Perez, 2008,).

This procedure of scanning for another elective position or work environment outside the current institute legitimately prompts turnover intention, and afterward to genuine turnover. A pursuit of employment is viewed as per noteworthy forerunner to the upcoming sendoff by a specific job. It's at last finishes with whichever the energy about one's present place after examination by the choices, or a proceeded with feeling of disappointment (Perez, 2008).

A progressively far reaching removal procedure was recognized by Steel and Lounsbury (2009) it reveals insight into arrangement of phases workers go over already them 
for all time choose to leave. Generally, the degree of work disappointment is one of the primary issues pushing workers to the ultimate goal of failing or actually leaving their company.

Steel and Lounsbury's model (2009) equally featured the quest for a vocation that joins the evaluation of any elective openings for work. In addition, it merits referencing that workers esteem, work recognitions, and impression of the work market impact withdrawal goals.

Fourthly, Greaves et al., (2013) directed investigation on a huge, UK-founded, freely supported association in the media segment. They considered Workers' turnover intention dependent on the segments of the Hypothesis of Arranged Conduct (TPB), to distinguish if those clarify the reasons for public aims specifically people. It is accepted that inspecting the forerunners of any conduct, together with the general setting, causes analysts to comprehend the procedures by which TPB parts are connected to goals.

On the off chance that this hypothesis is acquired to investigate ecological conduct in the working environment, it will speak to an effective device for foreseeing purposeful practices. As needs be, Arnold et al. (2006) assessed about 25,000 workers at 80 destinations over the UK, in view of TPB, and inspected the adjacent indicators of practices that invigorate people who mean to play out that conduct, the degree to whatever that conduct is measured, and the degree to which one believes in the advantages picked up after that apparent conduct.

TPB's three major components predict intentional behavior: attitude, subjective norm, and perceived regulation of behavior. Thus, TPB has without a doubt remained appropriately powerful on account of purposeful conduct, and has equally formed expectations around the individual increases and communal weights these are taken out of people known by the studies' turnover intention scales. Equally, public and mental predecessors are helpful when thought about in the area of turnover intention.

De Moura et al. (2009) exhibited there is a connection among employment fulfillment and hierarchical distinguishing proof with turnover expectation. Public Personality Hypothesis (SIT) underlines that there is a connection between hierarchical factors and public character, which has additionally been utilized in speculating about an assortment of authoritative factors, for example, profitability, professional stability, initiative, and turnover intention. Invariably, expectation of turnover intention in associations is connected straightforwardly to SIT, and subsequently, SIT is utilized broadly to foresee bunch helping decisions, dispositions, assessments, aims, and conduct.

Fifthly, Public Trade Hypothesis clarifies the connection among Workers and Firms. The public trade point of view is classified like a connection of correspondence of delight that's commonly contingent by the way detailing between two gatherings those stalks by the faith in trading and conveying a homogenous good standard (Loi et al., 2006). Along these lines, commonality of delight is going to treat to keep up a steady public framework via this standard of trade. Idea of public trade stayed equally clarified through taking note of separations in the outlook by financial trade (Liu, 2016).

By and large public trade is viewed like a huge haul try and includes fewer unmistakable or smooth workers assets, in spite of the fact that interestingly, monetary trade is well-known present moment. Inside the public trade, both the idea of the foreseen long term yields and durations isn't properly indicated, because profits remain really observed being commitments those are unknown, then the gatherings trade center around the ordinariness of correspondence in catapulting their very own commitments through future events.

Moreover, Karatepe and Shahriari (2014) applied public exchange theory, and observed its connection with turnover intention. The examination demonstrates this hypothesis gives bits of knowledge in a connection that happens among authoritative equity and turnover intention, where connections create by the movement of phase to wind up believing, faithful, 
and common responsibilities, it's especially pertinent when all colleagues, regardless of whether that be directors, managers, and Workers, are focused on explicit guidelines of trade.

In reality, public trades associate to a more noteworthy degree of mental contract, and capacity together with characterized close connection at an individual grade, organized by commitments of an open-finished nature. Advocates of monetary trade hypothesis propose that a connection occurs between the aim to quit a firm and how results make reasonableness, for example, towards pay and rewards.

At the end of the day, trust inside a cluster of workers is created and caused through a reasonable domain in a work environment concerning salary ranks that are ingrained and the assignment of remunerations, just as how relational conduct is kept up by class. Thus, Workers are fewer inclined to have the expectation to quit the firm when they keep up raised impression of equity inside their activity jobs.

Sixthly, the Activity entertainment hypothesis has been consolidated to contend that activity entertainment can change the impact of hierarchical equity concerning turnover intentions (Holtom et al., 2008). In particular, work entertainment can be believed to have different compelling consequences for the choice of a worker to remain in their activity or not. To put it plainly, much inserted workers would be less inclined to mean on sendoff their firm if they somehow happened to grip view of hierarchical equity inside their appreciation.

Thus, highly entertained workers who have an impression of decency in the general results would be more averse to show turnover expectations, particularly if this identified with deference of salary and incentive assignment or the nature of relational action by directors. The short degree of turnover intention additionally states to the issue that extremely inserted Workers are progressively associated with different activities and with an assortment of people, which implies that they won't charge huge number of chances, just as advantages, by quitting their firm (Karatepe \& Shahriari, 2014).

Seventhly, an examination by Yücel (2012) inspected the issue of turnover intention. Advocates of the Hypothesis of Frame of mind, what was proposed, hypothesize it's the best indicator that may be used to comprehend the conduct of an individual can really quantify the expectation of the person to play out that particular conduct. In addition, the investigation of Alexandrov et al. (2007) depended on Bagozzi's Frame of mind Hypothesis (evaluation prompts an enthusiastic reaction which prompts conduct). This hypothesis reflects over two mental components of atmosphere that describe a situation of retail administration. The principal measurement identifies with a worry.

Eighthly, Lee et al., (2006) tended to two hypotheses that clarify turnover conduct, then the main, which is talked about above, is Humanoid Wealth Hypothesis that features the significant jobs of information, aptitudes, and capacities that are brought to firms by workers. As an outcome, these components have different financial qualities and results that'll be straightforwardly influence a firm.

Workers by learning, aptitudes, and capacities are essential being overseen in a way that may invigorate their maintenance. Moreover, the investigation has referenced asset centered hypothesis, what recommends that the capacities, skills, and information of Workers ought to be viewed as uncommon, incomparable, and non-substitutable source of maintainable upper hand for a firm.

Ninthly, Udechukwu and Mujtaba (2007) have shown that monetary components and issues impact workers inside the working environment, alongside their public gatherings together in and out their Firms to a particular degree. So, shortages, needs, options, and together by inclinations are viewed as the most fundamental then close financial components that Workers as people normally face. 
It is realized that the assets that are coordinated to creation are limited, though single wants remain generally interminable. The connection between a lack of assets, also, vast needs and needs delivers weight, and powers people to look for different options in the encompassing condition. Subsequently, Workers move to another progressively good inclination or option from the accessible ones, and thusly, such choices that are taken by workers can be viewed as supporting the two speculations: Walk and Simon's idea of "satisfying": acknowledge an accessible choice as attractive in their overall hypothesis of hierarchical balance, and Vroom's idea of "valence": the consolidating intensity of a component in his anticipation hypothesis.

When all is said in done, it is said that the decisions made by an individual between elective strategies are coherently identified with mental occasions that happen successively nearby the conduct. As such, when the fundamental needs of workers are not fulfilled appropriately, their mental and corporeal ranks, and their employed efficiency all endure as an outcome.

There is a lack of intention to study turnover in the area of administration. Considerate the elements/factors that contribute to turnover expectation between scholastics, teachers, or speakers are urgent and important in creating corporate efficiency and producing skilled humanoid wealth for the whole country of Pakistan.

\section{Literature Review}

Hill et al., (2015) conducted a research and concluded that job with role ambiguity lead to conflict growth through surplus of negative perceptions and emotions and also handover workers to self-construal and self-comportment and turnover intention in workplace. (Chang, 2008) suggested that work role stressor has positive relationship with turnover intention and when there is low job satisfaction and firm commitment then worker seek for new job.

Another research by Rai (2015) entitled as "Turnover intention among long term care staff" concluded that worker who feel more role conflict, role ambiguity and role stress lead and intend to turnover and quitting the job. Elci et al., (2012) proposed that work related stress have positive and significance influence on turnover intention as compared to ethical leadership and leader effectiveness.

Yue et al., (2007) conducted study in Hong Kong and resulted that role of ambiguity has significance effect on workers turnover intention Many others of previous studies determined progressive connection among role ambiguity and turnover intention (Tongchaiprasit \& Ariyabuddhiphongs, 2016; Barak et al., 2006).

Goal orientation theory defines goal orientation as situated orientations for action in an achievement task (Dweck, 2005; Nicholls, 2009). Goal orientation encompasses the experience of a person in achievement situation and explains how and why people try to attain the achievement (Anderman \& Maehr, 2006). Generally, there were two major scopes of goal orientation delineated by goal orientation theory: Learning goal orientation and performance goal orientation.

Learning goal orientation is defined as the development of skills and competence or mastering a task with self-referential standards by an individual (Ames \& Archer, 2009). On the other hand, performance goal orientation is referred to as the demonstration in one's capacity relative to others and avoidance of being looked incompetent (Dweck, 2004). However, a study of Lin \& Chang (2005) proposed that performance goal orientation is unrelated to turnover intention as it is less concerned about personal learning and development compared to learning goal orientation.

Further, Lin and Changs (2005) finding discovered that performance goal orientation is not significantly associated to turnover intention. Thus, this research will only emphasis on 
the relationship between learning goal orientation and turnover intention. Learning goal orientation is identified by Dweck \& Leggett (2008) in terms of broader goals pursue by individuals. The concept of learning goal orientation is associated to how individuals interpret and respond to situations within their mental framework (Dweck, 2009).

According to Walle (2007), individuals who possess learning goal orientation incline to develop their aptitude from the current level and perceive it as workable attribute that can be improved through experience and effort. With the perception that ability is flexible, learning goal oriented individuals react to difficulties with lower task anxieties and treat failures as opportunities to gain new experience (Dweck, Hong and Chiu, 2013). Despite these explanations, Chiu, Hong and Dweck (2012) suggested that individuals may have different personality patterns across various domains.

Thus, the interpretation of learning goal orientation maybe different for those in the academic domain and those in the work domain. In the aspect of work domain, it can be explained the people with learning goals are more likely to search for new challenges, exhibit high effort and readiness for future tasks and pursuing adaptive response pattern in solving problems (Walle, 2007).

Owing to learning goal orientation represents a mind-set that workers are concerned with personal development, it is probable that they are highly sensitive to work environment that fails to provide them opportunities to learn. They may start to search for other employments that are able to offer better prospect and continuous development. In the case of adult students, they have the interest and perseverance to learn despite they need to juggle between their career and family. (Walle, 2010).

It is believed that they have high learning goal orientation that drives them to pursue their academic goals and gain new knowledge. As they are upgrading themselves with professional skills and competencies, it is very likely that they started to evaluate their current workplace and their work in relation to their ability. They may leave their present job if the workplace is no longer suitable for them in accordance with their ability. On the basis of the above explanation, it is postulated that learning goal oriented individuals may have higher turnover intention. (Dweck, 2012).

Based on research on learned helplessness and achievement motivation in school-age children, goal-oriented theories have evolved (Dweck, 1975; Nicholls, 2005, 2009). Dweck $(2005,2009)$ found that children who do not have different skills respond to school failures in a different way. Many kids acted in an adaptive manner-they attributed a lack of effort (while sustaining or intensifying it), faced successive obstacles, had high aspirations. Nevertheless, other children adopted non-adaptive behavior, viewing failure as a result of lack of ability, avoiding obstacles, increasing their resilience and commitment, while negative expectations are maintained.

In addition, helpless children were more likely to respond to failure with verbalizations irrelevant to the task and subsequent decreases in performance. It was proposed that helpless children may benefit from training that encourages different attributions and a focus on future success (Diener \& Dweck, 2014).

Learning goals encouraged seeking to increase ability and master new tasks and performance goals encouraged maintaining positive judgments and avoiding negative judgments to validate ability. The use of performance goals made individuals vulnerable to helpless response patterns and attributions. This information suggests that the varying outcomes for helpless and mastery individuals may be due to the fact that they are seeking to achieve different goals. 
These ideas continued to develop as performance and learning goals and mastery and helpless individuals were related to implicit theories. Dweck and Leggett (2008) found continued support that performance goals take a powerless pattern and expectations of learning contribute to a pattern of mastery. In addition, the helpless and mastery responses were described in detail. Individuals have different implicit theories that can vary by context or are general to all individual characteristics (Dweck, Chiu, \& Hong, 2015).

These implicit views of intelligence or ability are described in a theory of ability, or the implicit concepts that are held concerning the nature of ability. An incremental theory of ability is the belief that intelligence is changeable and can be increased through effort. (Dweck \& Leggett, 2013).

An entity theory of aptitude is the faith that aptitude is fixed and, thus, high effort is indicative of low ability. The helpless response begins a maladaptive pattern that discourages an individual from confronting obstacles and challenges. These helpless individuals use an entity theory of ability that leads them to feel inadequate after failure and avoid such situations.

The mastery individual uses an adaptive response pattern that seeks challenges and views failure as information that is useful for future success. Mastery-oriented individuals use an incremental theory of ability that leads them to conquer challenges through effort and to have optimism about future success. These implicit theories can lead individuals to have different views about goals, effort, and ability.

After many variations of measuring goal orientation had been developed, it became necessary for some standardization. Several authors have sought to resolve ongoing conceptual and methodological issues surrounding the study of goal orientation (Button et al., 2005; DeShon and Gillespie, 2005). Button and etal (2006) addressed many issues in goal orientation research and applied these concepts to a formal setting. These authors defined the primary goal orientation issues and developed a stable two factor scale.

Although goal orientation research proceeded, DeShon and Gillespie (2005) believed the state of the literature continued to be in conceptual and methodological disarray. These 12 authors sought to identify and define the issues and proposed a model for future goal orientation research. Both of these articles identify several central goal orientation issues including use as a trait or state measure, measurement practices, and dimensionality.

The use of goal orientation to describe a stable trait or a goal-driven state has been unclear from its first use in educational settings (Eison, 2006; Elliott and Dweck, 2008; Nicholls, 2010). There are many studies examining goal orientation as either a dispositional feature or as a public, but there is no consistent definition and the same term is used to describe many varying processes (DeShon and Gillespie, 2005). As stated previously, Elliott and Dweck (2008) sought to induce different types of goal orientations and Diener and Dweck (2011) suggested that helpless children be trained to have different attributions, both suggesting goal orientation is dependent on characteristics of the situation.

DeShon and Gillespie (2005) identify most research as defining goal orientation as a goal; yet here is slight difference between the numbers of studies using the goal or disposition definition. Studies describing goal orientation as a quasi-trait are not included in this comparison. The motivated action theory of goal orientation, proposed by DeShon and Gillespie (2005), defines goal orientation as a preferred set of achievement goals. That said, this theory also states that goal orientation may behave as a trait when a certain type of achievement goals are chronically pursued. It has been found, across several studies, that the three dimensions of personality are quite stable over a short period of time (Payne et al., 2007).

Still, there are few studies reviewing the flexibility of the objective orientation longer periods of time and these few have found that longer time periods weaken the coefficient of 
stability (Payne et al., 2007). Button and et.al (2009) asserted that goal orientation can be considered a rather steady personality Signifier that might be inclined by conditional differences.

In a meta-analysis of the goal orientation literature, Payne \& colleagues (2007) initiate that state measures had a stronger relationship with more distal consequences than trait measures. This study also found that trait measures of goal orientation predict over and above cognitive skills and character performance. Payne and et al (2007) propose areas of necessary future research examining both the public and attribute measures of goal orientation.

Further, DeShon and Gillespie (2005) state that the choice to measure goal orientation or manipulate achievement goals depends on the goals of the researcher. Thus, it may not be necessary to choose, but instead to consider the influences of both achievement goals and dispositional goal orientation in varying research endeavors. Measurement of goal orientation has been done in many different ways and for different settings. Single item measurements of goal orientation have not been found to be reliable (Button et al., 2006).

It is important to make sure that measures accurately determine the goal orientation of an individual. Several scales have been developed and validated for different uses. There are two that are most commonly used to assess dispositional goal orientation in formal settings. The measurement tool developed by Button and etal (2008) is meant to describe general goal orientation and be applicable to many different settings and has two dimensions.

VandeWalle (2007) developed a goal orientation measure that is specific to the work domain and measures levels on three different dimensions. Hafsteinsson, Donovan, and Breland (2007) criticize the measurement precision of both of these measures. More specifically, all five scales between the measures have low precision of measurement Button et al. (2008) and VandeWalle (2011).

The best of these was the Button et al. (2008) learning goal orientation scale, but even this had problems differentiating among respondents with high scores. The primary criticism of the VandeWalle (2009) measure is in regards to length. It is believed that adding several high-quality items to each VandeWalle (2006) scale would increase measurement precision in terms of validity (e.g., Hafsteinsson et al., 2007). Also, this research found VandeWalles (2006) learning measure to outperform both performance measures in terms of validity. This difference might explain consistent findings of stronger relationships with the learning goal orientation scale. Future research might improve and validate these goal orientation measures.

Goal orientation has been conceptualized as having anywhere from one to six dimensions.

The early work of Dweck assumes that goal orientation is a single range from helpless to mastery (e.g.; Diener \& Dweck, 2005; Dweck \& Leggett, 2006; Elliott \& Dweck, 2006). In response to confusion over describing what a zero on this single continuum would indicate, it was later proposed that learning and performance might be separate dimensions (Dweck, 2011). Button et al. (2013) found evidence that learning and performance goal orientations are not jointly limited or inconsistent.

Later, VandeWalle (2008) provided evidence of a separation of performance goal orientation into two further dimensions: performance approach and performance avoidance. Pintrich (2009) and Elliot and McGregor (2011) argue that a fourth dimension should be added to the achievement goal orientation literature that would include a learning avoidance dimension. While this model has received research attention, it is unclear how learning avoidance would differ from an individual high on both learning and performance avoid. Harackiewicz \& etal (2013) have proposed the usefulness of a different fourth dimension in describing motivational personality that is titled work avoidance. 
Elliot and Thrash (2001) have even proposed a model with six dimensions of goal orientation, crossing approach and avoidance with three definitions of competence. It is clear that a single dimension does not provide enough information, but there is need for further support for any of the proposed models of dimensionality to be generally accepted in all research. In an effort to further examine one of these propositions of goal orientation dimensionality, this study examines four dimensions of goal orientation, including learning, performance approach, performance avoid, and work avoidance.

Despite several decades of research and debate, there are still many theoretical and practical inconsistencies that must be examined by future research. DeShon and Gillespie (2005) criticize goal orientation theory for lack of clarity in the definition, disagreement over dimensionality and the use of profiles, stability, and measurement. It seems there is much more evidence required to resolve some of these inconsistencies and provide clarity for the examination and use of goal orientation. Despite a lack of clarity, research continues to define and explore goal orientation because of the usefulness in describing and predicting workplace attitudes and behaviors.

Turnover is a purposeful effort completed to leave someone's foundation (Lacity et al., 2008; Tett \& Meyer, 1993). Most scholars have seen it as a fundamental test that each firm looks at, mostly in the admins division (Mahmoud \& Reisel, 2014). To give up a position of work, a Worker for the most part quits his/her firm whichever deliberately or spontaneously. In both cases, it is likely to be quick antagonistic penalties for the firm as far as work performance and expenses. In this way, Firms more often than not plan to keep their workers sincerely joined to decrease their Turnover intention scale (Saeed et al., 2014).

This idea picked up the consideration for the two university students just as experts due to its changed impacts on the even working of Firms (Long et al., 2012). Turnover by and large it was for the most part examined as a result, however what significant for the firm isn't the result, however, what might lead workers toward this result (Paulsen, 2014). This examination highlighted a moderately novel idea named as turnover intention what's the degree with whom any Worker intends to quit his or her firm. The turnover intention scale showed a strong positive link with genuine turnover.

Former research uncovered Workers' turnover intention scale as the best beached sign for their quitting the firm (Byrne, 2005; Lambert et al., 2001; Steersman et al., 2004). As showed in the hypothesis of decided conduct, public expectations are the specific sign of someone's conduct (Ajzen 2010). This view is upheld in turnover writing by numerous scientists that guarantee that turnover intention for the most part bring about real turnover (Mobely et al., 1978; Kash et al., 2010; Cho and Lewis, 2012; Jung, 2010). Such aims influence worker's work and their practices as well as their companions' (Semmer et al., 2014).

Firms that miss very talented workers may have exasperating outcomes, for example, diminished hierarchical performance, and decreased administration conveyance and prompts managerial issues. It might equally add to expanded expenses of re-contracting and repreparing workers (Roodt \& Bothma, 2007; Sulu et al., 2010). Here the significant feature is that the Worker may not generally think about quitting an occupation as a choice. Their aim to leave relies upon their own and logical components (Bothma, 2011). In this way, it turns into the obligation of the firm to recognize the elements that can lessen the Turnover intention scale.

There are several components that can take positive work to increase the intended rate of turnover alike pressure (Chiu et al., 2005); governmental matters (Abbas et al., 2014); harassing (Houshmand et al., 2012); disappointment (Takase et al., 2005); job-community struggle (Alsam et al., 2013), and so on. Anyhow, Certain factors affect or decrease the scale 
of intention of turnover; for instance, hierarchical equity and nationality manner (Imran et al., 2014). One of the best significant factors in this detail is authoritative responsibility (Galletta et al., 2011; Rashid \& Raja, 2011; Dyk \& Coetzee, 2012; Yücel, 2012).

\section{Rationale}

Literature has tried to investigate it previously through very few researches. So, keeping the fact in front that the literature is still scarce there is a need to assess about the relationship between Role Ambiguity, Goal Orientation and Turnover Intention. On the other hand, in our indigenous context, there is lack of literature on role ambiguity, goal orientation and turnover intention.

\section{Objectives:}

To find out the relationship between demographic variables, role ambiguity, goal orientation and turnover intention among university teachers in the private sector.

To see the predicting role of role ambiguity in turn over intention among university teachers in the private sector.

To find out the moderating role of goal orientation in the relationship between role ambiguity and turnover intention.

To assess the gender differences in role ambiguity, goal orientation and turnover intention among university teachers in the private sector.

\section{Hypotheses:}

There would likely to be a significant relationship between role ambiguity, goal orientation and turnover intention in teachers of Private sector universities.

Role ambiguity would likely to predict turn over intention among teachers of Private sector universities.

Goal orientation would likely to moderate the relationship between role ambiguity and turnover intention.

There are likely to be gender differences in teachers of Private sector universities regarding role ambiguity, goal orientation and turnover intention.

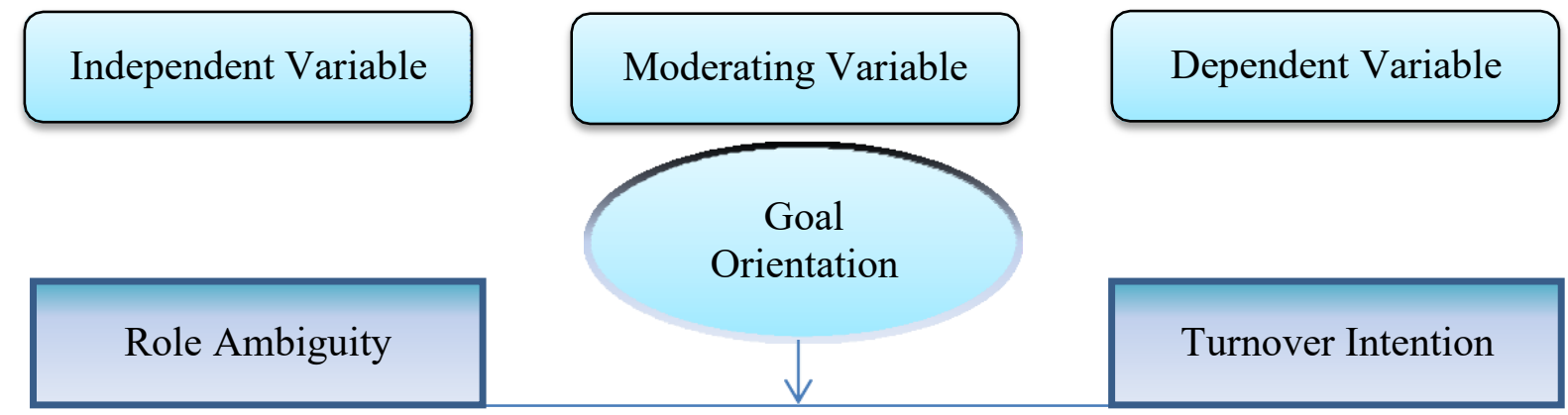

Figure 1.1 Research Proposed Model

The purposed research model shows that if Role Ambiguity is high in nature people must be less goal oriented and move towards turnover intent behavior, on the contrary if Role Ambiguity is low in its nature people must be more goal oriented than turnover intent behavior decreases.

\section{Method}




\subsection{Research Design}

The correlational research design has been used in this study.

\section{Operational Definitions}

\subsubsection{Role Ambiguity} 2001).

Role Ambiguity is confusion as to what a person in charge should do. (Singh \& Rhoads,

\section{Goal Orientation}

Goal orientation describes the disposition of an individual to improve or demonstrate ability to develop or demonstrate competence in circumstances of success or in individual differences in motivation (Payne et al., 2007; VandeWalle, 1997)

\section{Turnover Intention}

The purpose for turnover is the actions of workers intending to leave the job. (Mobley, 2009)

\section{Data Collection Places}

Data was obtained from Lahore's various private universities.

$>\quad$ Riphah International University Lahore

$>$ University Of Lahore

$>$ COMSATS University

$>\quad$ Minhaj University Lahore

\section{Sample}

The sample was calculated through G-power analysis. 250 faculty members (125 men and 125 women) from private sector universities, based in Lahore.

\section{Sampling Technique}

Sample was calculated through G Power analysis. In this study the technique of non- probably purposeful sampling was used. Purposive sampling refers to sampling units subjectively chosen by the investigator who is trying to collect a sample claiming to be population workers (Akins, 1994).

\section{Inclusion Criteria}

- This research included teaching faculty members from universities in the private sector between the ages of 30 and 45 years.

- Both men and women were included in this research.

\section{Exclusion Criteria}

- Teaching Faculty members of public sector universities were excluded.

- Non-Teaching staff was also excluded from the research study.

- Incomplete forms were excluded from the research

-

\section{Research Instruments}

20.1Demographic Information Sheet

It consisted of age, gender, family background, socioeconomic status, education, profession, monthly income, number of children, years of experience and department. 
21. Table 2.1

Demographic Information of Participants

\begin{tabular}{lccc}
\hline Variables & $F$ & $\%$ & $M(S D)$ \\
\hline Gender & & & $1.50(0.50)$ \\
Men & 125 & 50 & \\
Women & 125 & 50 & $1.22(0.44)$ \\
Monthly Income & & & \\
30000-80000 & 196 & 78.4 & \\
$81000-130000$ & 52 & 20.8 & \\
131000-180000 & 2 & 0.8 & $2.04(0.57)$ \\
Education Status & & & \\
MA/MSc & 36 & 14.4 & \\
MS/M.Phil. & 168 & 67.2 & \\
PhD & 46 & 18.4 & \\
Designation & & & $1.26(0.48)$ \\
Lecturer & 189 & 75.6 & \\
Assistant Professor & 57 & 22.8 & \\
Professor & 4 & 1.6 & \\
Years of Experience & & & $2.15(0.85)$ \\
Less than 2 & 47 & 18.8 & \\
3-7 & 140 & 56.0 & \\
8-12 & 48 & 19.2 & \\
13-17 & 9 & 3.6 & \\
18-22 & 6 & 2.4 & \\
Type of Employment & & & $1.17(0.38)$ \\
Regular & 208 & 83.2 & \\
Contract & 42 & 16.8 & \\
Marital Status & & & $1.57(0.91)$ \\
Married & 179 & 71.6 & \\
Single & 70 & 28.0 & \\
Divorced & 1 & 0.4 & \\
\hline
\end{tabular}

Note: $f=$ Frequency, $\%=$ Percentage, $M=$ Mean, $S D=$ Standard deviation.

The table shows the demographic data of the participants: 125 participants $(50 \%)$ of the respondents were male and 125 participants $(50 \%)$ were female. $(78.4 \%)$ people were with the salary figure of (30000-80000), (20.8\%) were with the salary figure of (81000-130000) and (0.8\%) people were with the salary figure of (131000-180000). (14.4\%) people having the degree of MA/MSc, $67.2 \%$ people having the degree of MS/M.Phil. and (18.4\%) people having the degree of $\mathrm{PhD}$. In this study $(75.6 \%)$ participants were lecturers, $(22.8 \%)$ participants were Assistant Professors and (1.6\%) participants were Professors. (18.8\%) participants were having experience of less than 2 years, $(56 \%)$ participants were having experience of (3-7) years, $(19.2 \%)$ participants were having experience of (8-12) years, (3.6\%) participants were having experience of (13-17) years and only (2.4\%) participants were having experience of (18-22) years. 
$(83.2 \%)$ participants were on regular basis and (16.8\%) participants were on contract basis.

According to the results $(71.6 \%)$ of the people were married, $(28 \%)$ people were single and only one was divorced $(0.4 \%)$.

\section{Standardized Research Instruments}

Role Ambiguity Scale (Rizzo et al., 1970)

Goal Orientation Scale (Button, Mathieu \& Zajac, 1996)

Turnover Intention Scale ( Roodt, 2004)

\section{Role Ambiguity Scale (Rizzo et al., 1970)}

Role Ambiguity was estimated utilizing Role Ambiguity Scale. It made out of fourteen items of which eight measure the quality of the job conflict variable and the rest measure the quality of the job uncertainty variable. As the focal point of ebb and flow research is on Role Ambiguity, so 6 things estimating Role Ambiguity has been utilized here. It is a 5-point Likert type scale appraised as "totally disagree $=1 "$ to "totally disagree $=5$ ". Scores for role ambiguity run from 6 to 42 with higher scores speaking to role ambiguity. As per Van Sell, Brief, and Schuler (1981, as referred to in Jackson \& Randall, 1985) this instrument was utilized in over $85 \%$ of concentrates on job conflict and uncertainty, being appeared to attractively gauge every last one of these two free and factorial recognizable factors has equally been observed to be psychometrically solid (Schuler, Aldag and Brief, 1977; Smith, Tisak and Schneider, 1993). Tang \& Chang (2010) announced scales with a Cronbach's Alpha Coefficient of 0.86 for role ambiguity and 0.89 for role conflict have strong inner continuity. Sample items include:

1. I feel certain about how much authority I have.

2. I have clear, planned goals and objectives for my job.

3.

\section{Goal Orientation Scale (Button, Mathieu \& Zajac, 1996)}

The goal orientation was measured using a button et al. (1996) measurement; including 8 items evaluating the orientation of learning goals and 8 items evaluating the orientation of performance goals. It is marked with a rating scale of Likert 6. Higher score on the questionnaire indicates optimal goal orientation and vice versa. In the current research performance goal orientation was measured, so 8 items of the questionnaire were included. For the learning goal orientation and performance goal orientation, prior reliabilities of. 84 and.82 was reported respectively (Button et al., 1996). Sample items include:

1. "I prefer to do things that I can do well rather than things that I do poorly"

2. "The opinions others have about how well I do certain things are important to me."

\section{Turnover Intention Scale (Roodt, 2004)}

Turnover intention (expectation to leave or remain) was estimated with a 15-item scale. It was created by Roodt (2004) as a measure for surveying workers' aims of either remaining with, or leaving an firm. It is scored on a 5-point Likert type rating scale; higher score on the survey show more prominent Turnover intention and the other way around. Jacobs (2005) and Martin (2007) demonstrated Roodt's (2004) poll to be both dependable $(\alpha=.913$ and $\alpha=$ .90 separately) and verifiably substantial. A Cronbach alpha coefficient of .80 for Turnover intention scale was accounted for by Bothma and Roodt (2013).

Sample items:

1. „How often have you considered leaving your job? 
2. „How often do you look forward to another day at work?e

\section{Procedure of Data Collection}

All standardized scales were used. Permission was obtained by the author of the scale. Data was collected from some private sector universities. A number of visits were continued for rapport building with the participants. The participants were asked for participation in the research then the purpose of the study was explained to them. Consent was taken from them. The instructions were given to them about administration of scales. Scoring of the scales was done with the help of scoring keys.

\section{Ethical Considerations}

The following ethical considerations were followed by the researcher throughout the study:

Synopsis was submitted to Supervisor and was approved by university.

Permission was taken from different concerned authorities.

Permission was taken from authors of scales.

Informed consent was taken from participants.

Participants were assured that their identity will not be disclosed to anyone.

In case of psychological harm, counseling was provided to them.

Confidentiality was maintained.

Participants were ensured that they have rights to know the findings of the research.

\section{Results}

A sample of 250 faculty members (125 men, 125 women) were selected from privatesector Lahore universities in the chapter analyzing and interpreting collected data in order to define the relationship of role ambiguity, goal orientation and turnover intention. The data gathered was analyzed with the version SPSS 21.

28. Table 3.1

Psychometric properties of Standardized Scales

\begin{tabular}{lccccccc}
\hline \multicolumn{1}{c}{ Scales } & $K$ & $M$ & $S D$ & $\begin{array}{l}\text { Range } \\
\text { Actual }\end{array}$ & $\begin{array}{l}\text { Range } \\
\text { Potential }\end{array}$ & Skew & $\alpha$ \\
& & & & & & & \\
\hline Role Ambiguity Scale & 6 & 24.97 & 4.68 & $1-5$ & $7-30$ & 1.24 & 0.90 \\
Goal Orientation Scale & 15 & 73.85 & 12.02 & $1-6$ & $18-90$ & 1.77 & 0.94 \\
Turnover Intention Scale & 15 & 39.66 & 13.08 & $1-5$ & $18-68$ & 0.69 & 0.92
\end{tabular}

Table shows that the alpha reliability of role ambiguity is excellent, cronbachs $\alpha .90$. This scale has 6 items and the mean score is $M=24.97(S D=4.68)$. The table also shows that the alpha reliability of goal orientation is excellent, cronbachs $\alpha$.94.This scale has 15 items and the mean score is $M=73.85(S D=12.02)$.Further table indicates that the alpha reliability of turnover intention is also excellent, cronbachs $\alpha .92$.This scale has 15 items and the mean score is $M=39.66(S D=13.08)$

\section{Table 3.2}


Summary of Inter Correlation for Scores on the Role Ambiguity, Goal Orientation and Turnover Intention

$\begin{array}{lllll}M & S D & \text { I } & \text { II } & \text { III }\end{array}$

$\begin{array}{lccccl}\text { I Role Ambiguity Scale } & 25.0 & 4.7 & - & .62^{*} & -.37^{*} \\ \text { II Goal Orientation Scale } & 73.9 & 12.0 & - & -.09^{*} \\ \text { III Turnover Intention Scale } & 39.7 & 13.1 & & & -\end{array}$

**. Correlation is significant at the 0.01 level (2-tailed).

Correlation matrix indicated that there is moderate positive relationship between role ambiguity and goal orientation $(r=.62, p<.01)$. Role ambiguity and turnover intention have moderate negative correlation, $(r=-.37, p<.01)$. The results also showed that there is weak negative relationship between goal orientation and turnover intention $(r=-.09, p<$ $.01)$.

30. Table 3.3

Predictor of Turnover Intention

\begin{tabular}{lrr}
\hline Predictor & $\beta$ & $\Delta R^{2}$ \\
& & \\
\hline Role Ambiguity & -.37 & .137 \\
$R^{2}$ & .14 & \\
$F$ & 40.37 &
\end{tabular}

$p<.01 * *$

Results indicated that role ambiguity is a significant predictor of turnover intention, $\beta=-.37$, $F=40.37, p<, 0.01$. The value of $R^{2}(.14)$ explained $14 \%$ variance in turnover intention accounted for by role ambiguity.

31. Table 3.4

Moderating role of goal orientation

\begin{tabular}{cccc}
\hline Predictor & $S E$ & $\beta$ & $t$ \\
\hline Role Ambiguity & .68 & .74 & 1.09 \\
Goal Orientation & .20 & .90 & 4.32 \\
(Moderator) & & & \\
Interaction & .009 & -.03 & -3.37 \\
$R^{2}$ & .20 & & \\
$F$ & $21.68^{* *}$ & & \\
\hline
\end{tabular}

$* * p<.05$

Results indicated that role ambiguity is a significant predictor of goal orientation, $\beta=.74, F$ $=21.68, p<.05$. The value of $R^{2}(.20)$ explained $20 \%$ Variance in the role of ambiguity in the 
direction of the goal orientation. Interaction effect shows that goal orientation moderates the relationship of turnover intention and role ambiguity.

32. Table 3.5

Descriptive Statistics for One way Manova

\begin{tabular}{llccc}
\hline Variable & Gender & $M$ & $S D$ & $N$ \\
\hline Role Ambiguity & Man & 24.95 & 5.09 & 125 \\
& Woman & 24.98 & 4.24 & 125 \\
& Total & 24.96 & 4.68 & 250 \\
Goal Orientation & Man & 73.29 & 13.03 & 125 \\
& Woman & 74.40 & 10.93 & 125 \\
Turnover Intention & Total & 73.85 & 12.02 & 250 \\
& Man & 41.18 & 12.97 & 125 \\
& Woman & 38.13 & 13.07 & 125 \\
& Total & 39.66 & 13.08 & 250 \\
\hline
\end{tabular}

Table indicated that there are 125 men and 125 women of private sector university teachers who have responded about their role ambiguity, goal orientation and turnover intention. There is not any significant difference between men and women in terms of their role ambiguity. As the mean score related to role ambiguity of men and women teachers is almost same and the p-value i.e. level of significance is .95 which is greater than 0.05 . As the mean score related to goal orientation of men and women teachers is almost same and the p-value i.e. level of significance is .46which is greater than 0.05 . It shows that there is not any significant difference between men and women teachers perception on their goal orientation. The table shows that the mean score related to turnover intention of men and women private sector university teachers is higher than the p-value i.e. level of significance is .06 which is greater than 0.05 . It indicates that there is not any significant difference between men and women of private sector university teacher's perception on their turnover intention.

33. Table 3.6

Impact of Gender

\begin{tabular}{llccccccc}
\hline Source & $\begin{array}{l}\text { Dependent } \\
\text { Variables }\end{array}$ & $S S$ & \multicolumn{1}{c}{ Df MS F Sig $\eta^{2}$} & Observed & & \\
& & & & & & & Power \\
\hline \multirow{3}{*}{ Gender } & RA & .064 & 1 & .064 & .003 & .957 & .000 & .050 \\
& GO & 77.28 & 1 & 77.28 & .534 & .466 & .002 & .113 \\
& TIS & 580.64 & 1580.64 & 3.42 & .065 & .014 & .453 \\
Error & RA & 5457.68 & 248 & 22.00 & & & & \\
& GO & 3592.24 & 248 & 144.76 & & & & \\
\multirow{5}{*}{ Total } & TIS & 42071.45 & 248 & 169.64 & & & & \\
& RA & 161308.00 & 250 & & & & & \\
& GO & 1399509.00 & 250 & & & & \\
& TIS & 435881.00 & 250 & & & & \\
\hline
\end{tabular}


Analysis of One way Manova indicated that the effect of gender on role ambiguity $F$

$=.003, p<.05$ is not significant. The effect of gender on goal orientation $F(1,248)=.534, p<$

.05 is also not significant and the effect of gender on turnover intention $F(1,248)=.065, p<$

.05 is not significant as well.

\section{Table 3.7}

Impact of Gender

\begin{tabular}{llllll}
\hline Variable & $\lambda$ & Hypothesis $d f$ & Sig & $\eta^{2}$ & $\begin{array}{l}\text { Observed } \\
\text { Power }\end{array}$ \\
\hline
\end{tabular}

$\begin{array}{llllll}\text { Gender } & .97 & 3 & .136 & .022 & .48\end{array}$

Analysis indicated that the effect of gender, $\lambda(3,247)=.97, p<.05$ is not significant.

\section{Discussion}

The results of the current research are discussed in the context of the previous researches, so that we can find out whether the results of the current research are related or different from the findings of previous researches.

First of all it was hypothesized that there would likely to be a significant relationship among role ambiguity, goal orientation and turnover intention in teachers of Private sector universities. My hypothesis was accepted and according to results there was a significant relationship between role ambiguity, goal orientation and turnover intention among the faculty members of private sector universities.

The study shows that if role ambiguity is high in nature people must be less goal oriented and move towards turnover intent behavior, On the contrary if role ambiguity is low in its nature people must be more goal oriented than turnover intent behavior decreases.

Results are supported by literature. Job with role ambiguity lead to conflict growth through surplus of negative perceptions and emotions and also handover workers to selfconstrual and self-comportment and turnover intention in workplace Hill et al., (2015).

In this regard, Yue et al., (2007) conducted study in Hong Kong indicated result that the role of ambiguity has significance impact on workers turnover intention. Many others of previous studies determined positive relationship between role ambiguity and turnover intention (Tongchaiprasit \& Ariyabuddhiphongs, 2016; Barak et al., 2006).

Secondly, it was hypothesized that Role ambiguity would likely to predict turnover intention among teachers of Private sector universities. My hypothesis has been approved. Results indicated that Role ambiguity was a significant predictor of turnover intention among teachers of Private sector universities.

The study shows that if role is unclear and ambiguous to the worker and he/she is unable to understand his/her responsibilities and tasks than there are more chance of appearing his/her turnover intent behavior.

Results are supported by literature. (Bline et al., 1991) find that, if there is too much ambiguity, workers continue to consider other potential ways of reducing their frustration and plan to leave the company. In addition, clarity of position is also linked positively to creativity (Panzanoet al, 2001).

Job clarity refers to how precisely an individual's intended collection of tasks is articulated. The reverse situation is the role ambiguity or the role complexity (Jansen and 
Gaylen, 1994). This means that role ambiguity has a negative and significant impact on the imagination of workers.

Thirdly, it was hypothesized that Goal orientation would likely to moderate the relationship between role ambiguity and turnover intention. My hypothesis was also approved. Results indicated that goal orientation is the significant moderator of role ambiguity and turnover intention.

The study reveals that goal orientation plays a moderating role in between role ambiguity and turnover intention as if rate of role ambiguity is high in its context, people are less goal oriented and turnover intent behavior increases, On the other hand if rate of role ambiguity is low in its context, people are more goal oriented and turnover intent behavior decreases. Hence proved that goal orientation is a significant moderator of role ambiguity and turnover intention.

Results are supported by literature. Research show that goal orientation plays an important role as a moderator in between role ambiguity and turnover intention. Goal orientation theory defines goal orientation as situated orientations for action in an achievement task (Dweck, 2005; Nicholls, 2009).

Goal orientation encompasses the experience of a person in achievement situation and explains why and how people are trying to attain the achievement (Anderman \& Maehr, 2006). Generally, there were two major dimensions of goal orientation delineated by goal orientation theory: Learning goal orientation and performance goal orientation.

The study of DeShon and Gillespie (2005) identifies most research as defining goal orientation as a goal; yet there is little difference between the numbers of studies using the goal or disposition definition. Studies describing goal orientation as a quasi-trait are not included in this comparison.

Motivated goal orientation behavior theory, proposed by DeShon and Gillespie (2005), defines goal orientation as a preferred set of achievement goals. That said, this theory also states that goal orientation may behave as a trait when a certain type of achievement goals are chronically pursued. It has been found, across several studies, that the three dimensions of personality are quite stable over a short period of time (e.g., Payne et al., 2007). The study shows that turnover is a purposeful effort done to leave one's foundation (Lacity et al., 2008; Tett \& Meyer, 1993). Several researchers have seen it as a fundamental test that each firm examines, particularly in its administration (Mahmoud \& Reisel, 2014).

Further, it was hypothesized that there is likely to be gender differences in teachers of Private sector universities regarding role ambiguity, goal orientation and turnover intention. The current hypothesis was not accepted and the results are non-significant. There are several reasons of the current results. One reason is that both genders are equally important in modern era.

Results are supported by literature. Many studies have found that there were no significant differences in gender in tasking, quality or performance-preventing goals (Phan, 2008; Abrahamsen et al., 2007; Smith \& Sinclair, 2005). Pintrich and Schunk (2002) reported that there are no significant differences in the goal form sought as a sex feature. Therefore, they comment on the need for further studies to examine gender differences in goal orientation.

\subsection{Conclusion}

It was concluded that present research would be a great contribution in the educational as well as organizational field. It can help the educational authorities and the head of companies to clear the role of the job to their workers and teaching staff as well. It was concluded that there was moderate positive relationship between role ambiguity and goal 
orientation. Role ambiguity and turnover intention are negatively correlated. The results also showed that there is weak negative relationship between goal orientation and turnover intention. Findings also revealed role ambiguity to be the most significant predictor of turnover intention. This research study concluded that it is very much important for a worker that his/her role of the job must be clear. It will be beneficial for both worker and firm as well.

\subsection{Limitations of the Research}

Limitations of the research include:

Sample was only taken from private sector universities of Lahore.

\subsection{Recommendations/Suggestions for future research}

The suggestions for future researchers include:

In future cross cultural research should be conducted.

This research study was conducted in educational settings but for future research it can also be conducted in firm settings as well.

\subsection{Implications}

The present research will be beneficial for variance fields such as for the educationist, industrialists, I/O psychologist, researchers and all other concerns. It can also be beneficial for business administration, industrial workers as well. The study will be significant for managing workers role in the firms. So it will help owners and Managers to make such policies to reduce turnover intention.

\section{Reference}

[1] Abramis, D. J. (1994). Work role ambiguity, job satisfaction, and job performance: Meta- analyses and review. Psychological reports, 75(3_suppl), 1411-1433.

[2] Arshad, H., \& Puteh, F. (2015). Determinants of turnover intention among employees.

[3] Journal of Administrative Science, 12(2), 1-15.

[4] Arshadi, N., \& Damiri, H. (2013). The relationship of job stress with turnover intention and job performance: Moderating role of OBSE. Procedia-Social and Behavioral Sciences, 84, 706-710.

[5] Bako, M. J. (2014). Role ambiguity and Role Conflict amongst university academic and administrative staff: a Nigerian case study.

[6] Bee, G. H., Mak, I., Jak, N. W., \& Ching, P. Z. (2014). Factors Of Job Turnover Intention Among Employees Of Private Universities In Selangor (Doctoral dissertation, UTAR).

[7] Bosselut, G., Heuzé, J. P., \& Sarrazin, P. (2010). Structure of the role ambiguity framework and validity in the French culture. Psychology of Sport and Exercise, 11(6), 471-478.

[8] Bothma, C. F., \& Roodt, G. (2013). The validation of the turnover intention scale. SA Journal of Human Resource Management, 11(1), 1-12.

[9] Button, S. B., Mathieu, J. E., \& Zajac, D. M. (1996). Goal orientation in organizational research: A conceptual and empirical foundation. Organizational behavior and human decision processes, 67(1), 26-48.

[10] Chong, P. W., Khor, W. H., Lee, J. L., Ooi, S. Y., \& Tan, Y. K. (2013). The impact of HRM practices on employee turnover intention in UTAR (Doctoral dissertation, UTAR). 
[11] Cole, B. (2014). The relationship between job demands, job resources, engagement, burnout and intention to quit (Doctoral dissertation, Stellenbosch: Stellenbosch University).

[12] Da Silva, N., Borlongan-Conway, M. D., \& Tokunaga, H. (2010). Employee Goal Orientation in Relation to Creative Performance. Review of Management Innovation \& Creativity, 94.

[13] De Clercq, D., \& Belausteguigoitia, I. (2017). Reducing the harmful effect of role ambiguity on turnover intentions: The roles of innovation propensity, goodwill trust, and procedural justice. Personnel Review, 46(6), 1046-1069.

[14] Elçi, M., Şener, İ., Aksoy, S., \& Alpkan, L. (2012). The impact of ethical leadership and leadership effectiveness on employees' turnover intention: The mediating role of work related stress. Procedia-Social and Behavioral Sciences, 58, 289-297.

[15] Farr, J. L., Hofmann, D. A., \& Ringenbach, K. L. (1993). Goal orientation and action control theory: Implications for industrial and organizational psychology. International review of industrial and organizational psychology, 8(2), 193-232.

[16] Grobelna, A. (2016). Role ambiguity: a problem or a challenge facing contemporary hospitality industry. The critical role of employees' creativity. International Journal of Contemporary Management, 14(3), 77-98.

[17] Harris, M., Tang, K. K., \& Tseng, Y. P. (2002). Optimal employee turnover rate: Theory and evidence.

[18] Imran, R., Allil, K., \& Mahmoud, A. B. (2017). Teachers turnover intentions: Examining the impact of motivation and organizational commitment. International Journal of Educational Management, 31(6), 828-842.

[19] Kelloway, E. K., \& Barling, J. (1990). Item content versus item wording: Disentangling role conflict and role ambiguity. Journal of Applied Psychology, 75(6), 738.

[20] Kim, S., Tam, L., Kim, J. N., \& Rhee, Y. (2017). Determinants of employee turnover intention: Understanding the roles of organizational justice, supervisory justice, authoritarian organizational culture and organization-employee relationship quality. Corporate Communications: An International Journal, 22(3), 308-328.

[21] Klein, H. J., Noe, R. A., \& Wang, C. (2006). Motivation to learn and course outcomes: The impact of delivery mode, learning goal orientation, and perceived barriers and enablers. Personnel psychology, 59(3), 665-702.

[22] Lai, J. Y., Chi, H. J., \& Yang, C. C. (2011). Task value, goal orientation, and employee job satisfaction in high-tech firms. African Journal of Business Management, 5(1), 76-87.

[23] Lu, L., Lin, X., \& Leung, K. (2012). Goal orientation and innovative performance: The mediating roles of knowledge sharing and perceived autonomy. Journal of applied social psychology, 42, E180-E197.

[24] Ngo-Henha, P. E. (2018). A review of existing turnover intention theories. International Journal of Economics and Management Engineering, 11(11), 27602767.

[25] Olusoga, O. A., Fasanmi, S. S., \& Olubunmi, O. Mediating Roles of Corporate GoalSetting, Goal-Orientation and Corporate Ethical Values on Work Attitudes of Bank Employees.

[26] Ongori, H. (2007). A review of the literature on employee turnover. 
[27] Palomino, M. N., \& Frezatti, F. (2016). Role conflict, role ambiguity and job satisfaction: Perceptions of the Brazilian controllers. Revista de Administração (São Paulo), 51(2), 165- 181.

[28] Rahman, W., \& Nas, Z. (2013). Employee development and turnover intention: theory validation. European journal of training and development, 37(6), 564-579.

[29] Ram, N., Khoso, I., Shah, A. A., Chandio, F. R., \& Shaikih, F. M. (2011). Role conflict and role ambiguity as factors in work stress among managers: A case study of manufacturing sector in Pakistan. Asian Social Science, 7(2), 113-118.

[30] Schuler, R. S., Aldag, R. J., \& Brief, A. P. (1977). Role conflict and ambiguity: A scale analysis. Organizational Behavior and Human Performance, 20(1), 111-128.

[31] Seijts, G. H., Latham, G. P., Tasa, K., \& Latham, B. W. (2004). Goal setting and goal orientation: An integration of two different yet related literatures. Academy of management journal, 47(2), 227-239.

[32] Soltani, I., Hajatpour, S., Khorram, J., \& Nejati, M. (2013). Investigating the effect of role conflict and role ambiguity on employees' job stress: Articulating the role of work-family conflict. Management science letters, 3(7), 1927-1936. 